\title{
Realizing Connectedness Goals? The Risk Regulation System in Relationships
}

\author{
Sandra L. Murray \\ University at Buffalo, State University of New York
}

Address all correspondence to Sandra Murray, Department of Psychology, Park Hall, University at Buffalo, State University of New York, Buffalo, NY, 14260-4110. E-mail: smurray@acsu.buffalo.edu. The preparation of this chapter was supported by a grant from the National Institute of Mental Health (MH 60105-02). 
Discerning the quality of another's caring is a preoccupying goal in romantic life. Petals are plucked off daisies, and innocuous events, such as a glance, frown, or smile, are imbued with meaning in the hopes of discerning whether another truly cares. Such attentiveness to the evidence is not surprising given the unique interdependence dilemma romantic relationships pose. Risking thoughts and behaviors that increase closeness necessarily increases both the likelihood and pain of rejection. Imagine that Sally has a bad day at work and comes to Harry for consolation. Her willingness to seek support is critical for establishing satisfying interactions, but in seeking support, she risks Harry’s criticism or rebuff. Moreover, the longterm pain of rejection only increases the more Sally comes to depend on Harry for comfort.

Given the pain of rejection and relationship loss (Baumeister \& Leary, 1995), people should be motivated to think and behave in ways that minimize dependence on the partner, and consequently, minimize the likelihood of being hurt (Murray, Holmes \& Collins, 2006). However, people need to risk substantial dependence (Kelley, 1979) to establish the kind of satisfying relationship that can fulfill basic needs for connection (Baumeister \& Leary, 1995). They need to behave in ways that give a partner power over their outcomes and think in ways that invest great importance in the relationship (Gagne \& Lydon, 2004; Murray, 1999). For instance, people in satisfying relationships excuse their partner's bad behavior (Rusbult, Verette, Whitney, Slovik \& Lipkus, 1991). They also respond to their partner’s needs as they arise, and trustingly, leave the timing of repayment up to the partner (Clark \& Grote, 1998).

The coincident need to risk and protect against rejection creates a basic dilemma of interdependence. The thoughts and behaviors that are critical for establishing satisfying close connections with others increase both the short-term risk of rejection and the long-term pain of rejection. This chapter extends a recent model of risk regulation developed to explain how people negotiate the resulting conflict between the goal of seeking connection and the goal of protecting against rejection (Murray et al., 2006).

\section{Balancing Connectedness and Self-Protection Goals}

Situations of dependence are fundamental to romantic life. One partner's actions 
constrain the other's capacity to satisfy important needs and goals. Such dependence is evident from the lowest to the highest level of generality. At the level of specific situations, couples are interdependent in multiple ways, ranging from deciding whose movie preference to favor on a given weekend to deciding what constitutes a fair allocation of household chores. At a broader level, couples must negotiate different personalities, such as merging one partner's laissez-faire nature with the other's more controlled style (Kelley, 1979).

It is situations such as these - situations where the partner's responsiveness to one's needs is in question - that routinely activate the risk of rejection in interpersonal life. Take the mundane example of a couple trying to decide whether to go to the current blockbuster action film or a contemplative arts film. Imagine that Sally confides to Harry that she believes that seeing the action film will help distract her from work worries, concerns that she fears the arts film Harry wants to see will compound. In making this request, Sally is putting her psychological welfare in Harry’s hands. Like most situations where sacrifice on Harry's part is required, she risks discovering that Harry is not willing to be responsive to her needs.

Given multiple layers of interdependence, people routinely find themselves in situations where they need to choose how much vulnerability (and thus how much potential for rejection) they safely can risk (Kelley, 1979). Throughout the course of the relationship, partners need to make iterative and often implicit choices between seeking connection (increasing dependence) and self-protection (decreasing dependence). Consequently, to risk being in the relationship, people need a system in place that functions to keep them feeling reasonably safe in a context of continued vulnerability (Murray et al., 2006).

The goal of the risk regulation system is to optimize the sense of assurance that is possible given one’s relationship circumstances (Murray et al., 2006). This sense of assurance is experienced as a sense of safety in one's level of dependence in the relationship - a feeling of relative invulnerability to hurt. To optimize this sense of assurance, this system functions dynamically, shifting the priority given to the goals of seeking closeness and protecting against rejection so as to minimize the perceived risks of rejection. 
Figure 1 illustrates the normative operation of this system. Situations that involve risk and vulnerability automatically activate the goal of seeking connection (Path A). This assumption reflects the functionalist argument that the most effective means of managing a capricious and dangerous world is to seek connection to others who will be motivated to meet one’s needs. It is consistent with models of attachment (Mikulincer \& Shaver, 2003), interdependence (Kelley, 1979), self-esteem (Leary \& Baumeister, 2000) and evolutionary models of altruism and social exchange (Tooby \& Cosmides, 1996).

Recent research in my laboratory further supports this proposition. Specifically, priming the general risks of interdependence motivates people to seek greater connection to romantic partners. People primed to think of a time when a significant other disappointed them report greater feelings of closeness to their dating partner (Murray, Derrick, Leder \& Holmes, 2007). Low self-esteem people primed to think of a time when a significant other disappointed them are also quicker to identify words associated with seeking connection (e.g., approach, vow, forgive) in a lexical decision task (Murray et al., 2007). Research on attachment processes points to a similar conclusion. Indirectly priming vulnerability by priming failure-related thoughts activates thoughts of seeking proximity to others (Mikulincer, Birnbaum, Woddis \& Nachmias, 2000) and increases the accessibility of a romantic partner’s name (Mikulincer, Gillath \& Shaver, 2002).

The goal of seeking connection then activates the risk regulation system (Path B). The supposition of this executive control system reflects the reality that others are not likely to be equally motivated to tend to one's needs. Some others, such as those that have been the source of past hurts, might actually be motivated to thwart one's needs. Consequently, the desire to seek connection should also activate a control system that helps people discern which others and which situations are safe - a kind of “stop” routine. Consistent with this logic, Leary and his colleagues believe that the need to protect against rejection is so important that people evolved a system gauging rejection threats (Leary \& Baumiester, 2000). They argue that self-esteem is simply a metric - a “sociometer” - that measures a person’s perceived likelihood of being accepted or rejected by others and then regulates appropriate approach behaviors. 
The need for a control system to regulate risk is amplified in romantic relationships because narrowing social connections to focus on one specific partner raises the personal stakes of rejection. In committing himself to Sally, Harry narrows the number of people he can rely on to satisfy his needs, and in so doing, makes his welfare all the more dependent on Sally's actions. In his routine interactions, Harry also does not need to seek acceptance from someone he perceives to be rejecting. However, in his relationship with Sally, he is often caught in the position of being hurt by the person whose acceptance he most desires.

The risk regulation system functions to direct Harry toward the situations where it feels safe to approach Sally and away from situations where caution seems needed. This control system requires three "if-then" contingency rules to regulate the pursuit of connectedness goals. These rules involve: (1) An "appraisal” rule that links situations of risk to the goal of gauging a partner’s acceptance (Path C), (2) a "signaling” rule that links perceptions of a partner’s acceptance or rejection in these situations to the experience of gratified or hurt feelings and coincident gains or losses in self-esteem (Path D), and (3) a "behavioral response" rule that links perceptions of a partner's acceptance or rejection to the willingness to increase interdependence (Path E). These rules operate in concert to prioritize self-protection goals (and the assurance that comes from distance) when the perceived risks of rejection are high or connectedness goals (and the assurance that comes from closeness) when the perceived risks of rejection are low.

Appraisal rules. Appraisal rules abstract inferences about a partner's responsiveness from the ongoing stream of events. They take the form "if risky situation, then gauge acceptance or rejection” (Path C). For people to pursue connectedness goals in risky situations, their interpretation of events must provide reason to trust in the partner's responsiveness to need (Reis, Holmes \& Clark, 2004; Tooby \& Cosmides, 1996). The experiences that afford optimistic expectations about responsiveness likely vary across situations, relationships, and perhaps cultures. However, the common diagnostic that affords confidence in a partner's responsiveness is the perception that a partner perceives qualities in one worth valuing - qualities that are not readily available in others, making one worth the sacrifice. In independent cultures, this sense of 
confidence requires the inference that a partner perceives valued traits in the self (Murray, Holmes \& Griffin, 2000). In interdependent cultures, this sense of confidence requires the further inference that a partner’s family also values one’s traits (MacDonald \& Jessica, 2006).

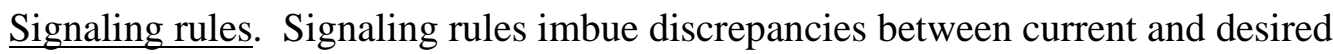
appraisals of a partner's regard with affect (Berscheid, 1983). They take the form "if accepted or rejected, then internalize” (Path D). Perceiving rejection or drops in a partner's acceptance or admiration hurts and threatens people’s desired conceptions of themselves as being worthy of interpersonal connection (Leary \& Baumeister, 2000). In contrast, perceiving acceptance or gains in a partner's acceptance or admiration affirms and bolsters people’s overall sense of selfworth. Thus, for people to pursue connectedness goals in risky situations, the prospect of approaching a specific partner should affirm rather than threaten the self.

Behavioral response rules. Behavioral response rules turn the perception of acceptance or rejection, and co-incident gains or losses in self-esteem, into action. They take the form "if feeling accepted/affirmed or rejected/hurt, then regulate dependence” (Path E). Specifically, behavioral response rules operate to ensure that people only risk as much future dependence as they feel is reasonably safe given recent experience.

When a partner's general regard is in question, and rejection seems more likely, people tread cautiously, reserve judgment, and limit future dependence on the partner. Consistent with this logic, experiencing rejection elicits a social pain akin to physical pain so as to trigger automatic responses, such as aggression, that increase physical or psychological distance between oneself and the source of the pain (MacDonald \& Leary, 2005). In interactions with a romantic partner, a first line of defense might involve limiting the situations people are willing to enter within their relationships - becoming less willing to seek support, disclose, or respond communally to the partner's needs, for instance. A second line of defense might involve shifting the symbolic value attached to the relationship itself - derogating the partner's traits or devaluing the importance of intimacy.

However, when confident of a partner's general regard, people can more safely risk 
increased dependence in the future - entering into situations where the partner has control over their immediate outcomes, forgiving transgressions, attaching greater value to their partner's qualities, and risking a stronger sense of commitment to the partner and relationship. Suggesting that felt acceptance is a relatively automatic trigger to safety and the possibility of connection, unconsciously primed words that connote security (e.g., accepted) heighten empathy for others (Mikulincer, Gillath, Halevy, Avihou, Avidan \& Eshkoli, 2001), diminish people’s tendency to derogate outgroup members (Mikulincer \& Shaver, 2001), and increase people’s desire to seek support from others in dealing with a personal crisis (Pierce \& Lydon, 1998).

\section{How Perceived Regard Controls Rule Sensitivity}

For the risk regulation system to be functional, it needs to adapt itself to suit specific relationship circumstances. If Sally generally perceives Harry to be responsive to her needs, distancing herself from Harry at the first sign of his insensitivity is not likely to be the optimal means of sustaining the needed sense of assurance. However, if Sally generally perceives Harry to be unresponsive, such a response might be Sally's best available means of sustaining some minimal sense of safety from harm. Accordingly, to respond dynamically and efficiently to ongoing events, the risk assessment system depicted in Figure 1 needs a heuristic means of estimating the level of risk inherent in specific situations.

Figure 2 illustrates how this calibration process occurs. In this individual differences perspective on the risk regulation system, people's global or cross-situational sense of confidence in a partner's positive regard and love acts as a general arbiter (Murray et al., 2006). Specifically, feeling more or less positively regarded by a partner interacts with specific event features to control the sensitivity of the appraisal, signaling, and behavioral response rules people adopt in specific situations. For people who generally feel less valued by the partner, the risk regulation system should have a lower threshold for activation, and when operative, generally prioritize self-protection over connectedness goals. By contrast, for people who generally feel more valued by the partner, the risk regulation should have a higher threshold for activation, and when operative, generally prioritize connectedness over self-protection goals. Consequently, 
when interpersonal vulnerability and risk activate the goal of seeking connection, people who generally feel more valued by their partner should be more likely to actualize this goal than people who generally feel less valued. Why would this be the case?

When Self-Protection Goals Trump Connectedness Goals

General expectations of rejection, such as those embodied in attachment anxiety or low self-esteem, make specific rejection experiences all the more painful and all the more motivating (Leary \& Baumeister, 2000; Nezlek, Kowalski, Leary, Blevins \& Holgate, 1997). For people who generally feel less positively regarded by a specific partner (i.e., lows), situated rejection experiences hurt more because they pose a greater proportional loss to a more precarious, generalized sense of their worthiness of interpersonal connection. Accordingly, they are in need of a risk regulation system that prioritizes self-protection goals (Higgins, 1996) - one that quickly detects rejection (“if risky situation, then perceive rejection”), strongly signals the possibility of further hurt ("if rejected, then internalize), and motivates them to take defensive action sooner rather than later ("if rejected, then limit dependence”). Such a system best affords lows some minimal sense of continued assurance in the relationship.

Appraisal rules. Imagine that Sally gets criticized at work for failing to complete a project. Such situations activate the attachment system and the need to seek another's literal or symbolic validation (Collins \& Feeney, 2000). However, if Sally questions Harry’s ongoing positive regard, she may be reluctant to disclose her personal failing for fear he might be disparaging of her. Instead, such a situation may activate "if-then” contingencies that link her failures to Harry's likely rejection. Consistent with this logic, people who are low in self-esteem - that is, people who generally doubt the acceptance of others - see interpersonal acceptance as conditional in nature (Baldwin \& Sinclair, 1996). For instance, low self-esteem dating intimates react to induced doubts about their intelligence or considerateness by expressing greater concerns about their partner’s likely rejection (Murray et al., 1998). Similarly, in a daily diary study conducted by my laboratory, low self-esteem married women saw their failures at work as signs of their spouse’s rejection at home (Murray, Rose, Bellavia \& Griffin, 2006). 
Now imagine that Sally comes home to find Harry in an irritable mood, grumbling about the lack of food in the fridge, and the fact that Sally had promised to replenish the fridge's contents by day's end. If Sally generally feels less valued by Harry, she may have difficulty attributing such negative events to some specific feature of the situation, such as his fatigue. Instead, Sally may attribute such grumbling to an interpersonal disposition - his broader displeasure with her. In the daily diary study, married intimates who generally felt less valued by their partner felt more rejected on days after their partner had just been in a bad mood, a mood that had nothing to do with them or the relationship (Murray, Bellavia et al., 2003). People who are less trusting of their partner's responsiveness also react to reminders of past transgressions by perceiving more hurtful intent in the discussion of a current problem (Holmes \& Rempel, 1989).

Research utilizing dispositional proxies for perceptions of a specific partner's regard yields parallel results. For instance, dating intimates who doubt their partner's regard due to low self-esteem over-interpret their dating partner’s hypothetical negative moods, seeing them as symptomatic of their partner's ill feelings toward them (Bellavia \& Murray, 2003). Low, but not high, self-esteem people also react to experimentally-induced signs of a partner's irritation by anticipating rejection (Murray et al., 2002). Dating intimates who are high on attachment-related anxiety about acceptance (and are likely to question their specific partner's acceptance) interpret a partner's misdeeds in suspicious ways that are likely to exacerbate hurt feelings (Simpson, Rholes \& Phillips, 1996). They also interpret daily conflicts as a sign of their partner's waning commitment (Campbell et al., 2005) and they even interpret a partner's ambiguous attempts to be supportive as intentionally hurtful (Collins and Feeney, 2004).

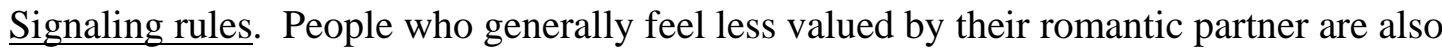
readily hurt by rejection, reflecting the operation of a highly sensitive signaling system. In the diary study, global perceptions of the spouse's regard determined how much daily concerns about a partner's rejection deflated state self-esteem (Murray, Griffin et al., 2003). People who generally felt less positively regarded by their partner felt worse about themselves on days after they experienced greater than usual level of anxiety about their partner’s acceptance (as 
compared to low anxiety days). In a conceptually parallel experiment, low self-esteem dating intimates responded to induced fears that their partner perceived important faults in them by questioning their own self-worth (Murray et al., 2002, Experiment 3).

Behavioral response rules. The existing evidence further suggests that people who feel less valued by their partner respond to perceived rejections by reducing interdependence, thwarting connectedness goals. As one example, priming general interpersonal risk (by having people think of a time when a significant other disappointed them) increases the desire to connect to the partner, especially for low self-esteem people. Despite this heightened need, they are unwilling to take the concrete, interdependence-increasing steps, such as letting a partner make decisions that affect them, to facilitate this goal (Murray et al., 2007). Instead, people who generally feel less valued, such as those with low self-esteem, respond to risk by diminishing their partner’s value, thereby giving a partner less potential power to hurt them.

For instance, people with low self-esteem respond to induced anxieties about their partner's possible rejection by depending less on their partner as a source of self-esteem and comfort (Murray et al., 1998). They also evaluate their partner's qualities more negatively (Murray et al., 1998; Murray et al., 2002). These devaluing processes also emerge whether these acute rejection anxieties are imagined in response to a newly discovered fault in the self (Murray et al., 1998) or arise in response to the partner’s behavior (Murray et al., 2002). In the daily diary study (Murray, Bellavia et al., 2003), people who generally felt less positively regarded responded to feeling acutely rejected by their partner one day by treating their partner in colder, more critical ways the next day. These reactions emerged even though the partners of people who felt less valued were not actually upset with them when lows felt most rejected.

Other research further illustrates how risky situations activate distancing attempts for people who generally feel less valued by a specific partner. Women higher in attachment-related anxiety display greater anger towards their partner in a situation in which their partner may not have been as responsive as they hoped (Rholes, Simpson \& Orina, 1999). After discussing a serious relationship problem, more anxiously attached men and women also reported greater 
anger and hostility (as compared to controls who discussed a minor problem), and they downplayed their feelings of closeness and commitment (Simpson et al., 1996). People high on attachment-related anxiety also react to higher levels of daily conflict by minimizing their feelings of closeness to their partner (Campbell et al., 2005). Moreover, women high on chronic rejection sensitivity respond to a potential partner's disinterest by evaluating that partner more negatively (Ayduk et al., 1999). They are also more likely to initiate conflicts on days after they felt rejected by their romantic partner (Ayduk et al., 1999).

\section{When Connectedness Goals Trump Self-Protection Goals}

For people who generally feel more positively regarded by a specific partner (i.e., highs), there is little need for such an easily activated and self-protectively calibrated risk regulation system. For them, specific rejections pose a smaller proportional loss to a comparably rich resource. Instead, the goal of maintaining the desired level of confidence in the partner's positive regard and caring is likely to prevail (Murray, Bellavia et al., 2003; Murray, Griffin et al., 2003). A control system that functions to prioritize connectedness goals thus better affords highs a continued sense of assurance or safety in the relationship.

In appraising the meaning of specific situations of dependence, people who generally feel more positively regarded set a high threshold for detecting rejection. In fact, specific situations of risk should activate "if-then" contingencies that link potential threats to motivated cognitive processes that bolster and protect perceptions of the partner's acceptance and caring ("if dependent, then perceive acceptance”). Even when highs feel rejected, general expectations of partner acceptance should dull the sting of specific hurts ("if rejected, then resist internalizing”), protecting self-esteem from most rejection experiences. General expectations of acceptance should even give highs reason to believe that seeking greater closeness to the partner will minimize the likelihood of future hurts ("if rejected, then increase interdependence”).

Appraisal rules. Rather than being quick to perceive rejection, people who feel more valued by their partner react to risky situations by affirming their partner's acceptance and love. For instance, high self-esteem participants reacted to failure on a purported test of intelligence by 
exaggerating their partner’s love (Murray et al., 1998). In the diary study, on days after participants felt badly about themselves, people who generally believed their spouse regarded them more positively actually felt more loved and accepted (Murray, Griffin et al., 2003). People who felt more positively regarded by their spouse even felt more loved and accepted by their partner on days after they reported more than their usual amount of conflict or negative partner behavior (and thus had greater actual reason to distrust their partner).

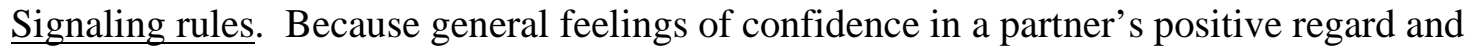
acceptance blunt the sting of specific rejections, there is little need for a strong signaling system. Instead, for highs, situated feelings about their own worth should be reasonably immune to perceived rejections. Consistent with this logic, anxieties about a partner's rejection do not diminish state self-esteem for people who generally feel more valued by their partner (Murray, Griffin et al., 2003). Moreover, the possibility of a dating partner's annoyance or irritation does not trigger acute self-doubts among high self-esteem people (Murray et al., 2002).

Behavioral response rules. For people who feel more positively regarded, perceiving acute rejections motivates interdependence increasing behaviors, fostering the realization of connectedness goals. Dating intimates who tend to feel more positively regarded by virtue of higher global self-esteem also react to induced self-doubts by reporting greater dependence on their partner's reassurance as a source of self-esteem (Murray et al., 1998). They even respond to induced concerns about their dating partner's likely annoyance with them by reporting greater feelings of closeness to that same partner (Experiment 2, Murray et al., 2002). In the daily diary study, married intimates who generally felt more positively regarded actually drew closer to their partner on days after they felt most rejected (Murray, Bellavia et al., 2003). Similarly, people low on attachment-related anxiety come to value their partner more after discussing a serious than a minor conflict (Simpson et al., 1996). 


\section{Is Risk Assessment an Executive Control System?}

Is the risk assessment system indeed an executive control system - one that is brought on-line with the activation of connectedness goals? If it is, a number of consequences should follow. First, activating the general goal of approaching a desired state should activate the signature style underlying that person's risk assessment system. For people prone to distrust a specific partner's regard, priming approach goals should result in a pattern of automatic (i.e., uncontrolled) associations that reflect the desire to connect and avowed (i.e., controlled) intentions that reflect the need to distance. In a sense, the heart might seek closeness, whereas the mind resists it. For people prone to trust a specific partner's regard, however, priming approach should result in consistent controlled and uncontrolled responses.

To examine these hypotheses, my laboratory conducted a series of experiments where we subliminally primed approach goals (using a word categorization task). We then measured positive implicit associations to one's dating partner and explicit reports of closeness (Murray et al., 2007). As expected, low self-esteem people primed with approach goals were quicker to associate desirable qualities with their partner in a reaction time task. Nonetheless, they reported diminished feelings of closeness on the explicit measure, reflecting the activation of selfprotection goals. By contrast, high self-esteem people primed with approach evidenced greater feelings of connection to their dating partner on both the implicit and explicit measures.

Second, if the risk assessment system is indeed a control system, even people who normally prioritize self-protection goals should pursue connectedness goals when executive control is usurped. For instance, a low self-esteem Sally should look more like a high selfesteem Harry in situations where Sally’s capacity to self-protect are compromised. To examine this assumption, my laboratory recently conducted an experiment where we manipulated both risk salience (i.e., thinking of a time when a significant other disappointed them vs. thinking of their school commute) and cognitive busyness (i.e., remembering an alphanumeric strength vs. not). We then measured participants' willingness to risk increased interdependence (e.g., willingness to disclose to the partner, let the partner make decisions). Suggesting that self- 
protection requires greater cognitive control than seeking connection, even low self-esteem participants reacted to risk salience by increasing interdependence when they were cognitively busy. When they were in greater control of their cognitive resources, however, they successfully resisted the pressure to increase connection in the face of risk (Murray et al., 2007).

Third, if the risk assessment system is indeed a functional control system, its operation should also be sensitive to the comparable strength of connectedness and self-protection goals. Specifically, even people normally prone to self-protect should risk greater connection in those situations where the need to connect is heightened. For instance, a low self-esteem Harry should be more willing to risk disclosing to Sally in those situations where he really needs reassurance (i.e., stronger connection goal) and approaching others seems riskier still. To examine this assumption, we conducted an experiment where we manipulated both risk salience (i.e., thinking of a time when a significant other disappointed them vs. thinking of their school commute) and the strength of connectedness goals (i.e., priming approach goals with a word categorization task vs. not). We then again measured the willingness to risk interdependence. As expected, low self-esteem people who were reminded of the risks of trusting others only reported greater willingness to risk interdependence with their own partner when their desire to seek connection was heightened through the implicit activation of approach goals (Murray et al., 2007).

\section{The Self-Defeating Effects of Overly Sensitive Risk Assessment Systems}

As the experience of slights and hurts at the hands of a romantic partner is inevitable, the challenge in maintaining a satisfying relationship rests in preventing such situated threats from thwarting connectedness goals. However, for people who feel less positively regarded, the slightest offense is likely to be seen as a sign of impending rejection, motivating them to selfprotect and distance themselves from the sting of any further perceived slights. Such efforts to minimize risk would be appropriate if people who feel less valued actually possessed partners who valued and loved them less, and treated them less well. This does not appear to be the case. Intimates who felt less valued in the diary study still perceived rejection in their partner's behavior, and reacted defensively to feeling hurt even when the nature of the partner's behavior 
and actual regard for them was held constant (Murray, Bellavia et al., 2003).

Ironically, the desire to protect against hurt seems to lead people who are trying to find acceptance to undermine the resource of an admiring partner that they need to preserve. For instance, women who chronically anticipate rejection behave more negatively toward their dating partner during conflicts and elicit more rejecting behavior in that specific instance (Downey et al., 1998). Moreover, on days after rejection sensitive women feel acutely rejected by their dating partner, their partner reports greater dissatisfaction (Downey et al., 1998). In the diary study reported by Murray, Bellavia et al. (2003), the partners of people who felt less positively regarded (correctly) believed they were the target of more hurtful and rejecting behaviors on days after lows had felt most vulnerable. Even though they were not annoyed or upset initially, the partners of lows were also more likely to see lows as being selfish and unappreciative on days after lows had felt most hurt and vulnerable.

By putting self-protection at a greater premium than connection, people who feel less positively regarded may create long-term interpersonal realities that defeat their hopes and confirm their fears. Supporting this analysis, a longitudinal daily diary study of married couples suggests that the chronic activation of self-protective appraisal, signaling and behavioral response rules has a corrosive effect on relationships over time (Murray, Bellavia et al., 2003; Murray, Griffin et al., 2003). In this sample, relationship difficulties were more likely to arise when the "if-then" contingencies underlying people's cognition, affect and behavior mirrored the “if-then” contingencies evident among people who feel less valued by their partner.

First, satisfaction declined when people’s on-line systems for appraising rejection threats were calibrated in a more self-protective fashion. In particular, when women linked their own personal self-doubts to their husband's lessened acceptance, their husband reported relatively greater declines in satisfaction over time (Murray, Griffin et al., 2003; Murray, Griffin, Rose \& Bellavia, 2006). Second, satisfaction declined when people’s signaling systems were more sensitive to rejection. When people reacted to anxieties about rejection by reporting diminished self-esteem the next day, their partner reported significantly greater declines in satisfaction. 
Third, when women's behavioral response to feeling rejected was to self-protect and behave negatively, their husband's satisfaction declined over the year (Murray, Griffin et al., 2003).

\section{Conclusion}

On the brighter side, close romantic relationships offer a unique opportunity for the fulfillment of connectedness goals. On the darker side, the prospect of rejection and relationship loss threatens a profound hurt (Baumeister \& Leary, 1995). Given such stakes, people only allow themselves to risk seeking connectedness when they trust in their partner's ongoing positive regard and acceptance. People who find this sense of assurance typically feel safe to prioritize connectedness goals. However, people who struggle to find this sense of assurance self-protect - thinking and behaving in ways that provide a sense of safety in the short term but can often alienate the partner and elicit rejection. 


\section{References}

Ayduk, O., Downey, G., Testa, A., Yen, Y., \& Shoda, Y. (1999). Does rejection elicit hostility in rejection sensitive women? Social Cognition, 17, 245-271.

Baldwin, M. W., \& Sinclair, L. (1996). Self-esteem and "if...then” contingencies of interpersonal acceptance. Journal of Personality and Social Psychology, 71, 1130-1141.

Baumeister, R. F., \& Leary, M. R. (1995). The need to belong: Desire for interpersonal attachments as a fundamental human motivation. Psychological Bulletin, 117, 497-529.

Bellavia, G., \& Murray, S. L. (2003). Did I do that? Self-esteem related differences in reactions to romantic partners' moods. Personal Relationships, 10, 77-96.

Berscheid, E. (1983). Emotion. In H. H. Kelley, E. Berscheid, A. Christensen, J. H. Harvey, T. L. Huston, G. Levinger, E. McClintock, L. A. Peplau, and D. R. Peterson (Eds.), Close relationships (pp. 110-168). New York: W. H. Freeman.

Campbell, L., Simpson, J. A., Boldry, J., \& Kashy, D. A. (2005). Perceptions of conflict and support in romantic relationships: The role of attachment anxiety. Journal of Personality and social Psychology, 88, 510-531.

Clark, M. S., \& Grote, N. K. (1998). Why aren’t indices of relationship costs always negatively related to indices of relationship quality? Personality and Social Psychology Review, 2, 2-17.

Collins, N. L., \& Feeney, B. C. (2000). A safe haven: An attachment theory perspective on support seeking and caregiving in intimate relationships. Journal of Personality and Social Psychology, 78, 1053-1073.

Collins, N. L., \& Feeney, B. C. (2004) Working models of attachment shape perceptions of social support: Evidence from experimental and observational studies. Journal of Personality and Social Psychology, 87, 363-383.

Downey, G., Freitas, A. L., Michaelis, B., \& Khouri, H. (1998). The self-fulfilling prophecy in close relationships: Rejection sensitivity and rejection by romantic partners. Journal of Personality and Social Psychology, 75, 545-560. 
Gagne, F. M., \& Lydon, J. E. (2001). Mind-set and relationship illusions: The moderating effects of domain specificity and relationship commitment. Personality and Social Psychology Bulletin, 27, 1144-1155.

Higgins, E. T. (1996). The "self digest": Self-knowledge serving self-regulatory functions. Journal of Personality and Social Psychology, 71, 1062-1083.

Holmes, J. G., \& Rempel, J. K. (1989). Trust in close relationships. In C. Hendrick (Ed.), Review of personality and social psychology: Close relationships, (Vol. 10) (pp. 187-219). Newbury Park: Sage.

Kelley, H. H. (1979). Personal relationship: Their structures and processes. Hillsdale, NJ: Erlbaum.

Leary, M. R., \& Baumeister, R. F. (2000). The nature and function of self-esteem: Sociometer theory. In M. P. Zanna (Ed.), Advances in experimental social psychology, Vol. 32 (pp. 2-51). San Diego, CA: Academic Press.

MacDonald, G., \& Jessica, M. (2006). Family approval as a constraint in dependency regulation: Evidence from Australia and Indonesia. Personal Relationships, 13, 183-194.

MacDonald, G., \& Leary, M. R. (2005). Why does social exclusion hurt? The relationship between social and physical pain. Psychological Bulletin, 131, 202-223.

Mikulincer, M., Birnbaum, G., Woddis, D., \& Nachmias, O. (2000). Stress and accessibility of proximity-related thoughts: Exploring the normative and intra-individual components of attachment theory. Journal of Personality and Social Psychology, 78, 509-523.

Mikulincer, M., Gillath, O., Halevy, V., Avihou, N., Avidan, S., \& Eshkoli, N. (2001). Attachment theory and reactions to others' needs: Evidence that activation of the sense of attachment security promotes empathic responses. Journal of Personality and Social Psychology, 81, 1205-1224.

Mikulincer, M., \& Shaver, P. R. (2001). Attachment theory and intergroup bias: Evidence that priming the secure base schema attenuates negative reactions to outgroups. Journal of Personality and Social Psychology, $\underline{81}, 97-115$. 
Mikulincer, M., \& Shaver, P. R. (2003). The attachment behavioral system in adulthood: Activation, psychodynamics, and interpersonal processes. In M. Zanna (Ed.), Advances in experimental social psychology (Vol. 35, pp. 52-153). New York: Academic Press.

Murray, S. L. (1999). The quest for conviction: Motivated cognition in romantic relationships. Psychological Inquiry, 10, 23-34.

Murray, S. L., Bellavia, G., Rose, P., \& Griffin, D. (2003). Once hurt, twice hurtful: How perceived regard regulates daily marital interaction. Journal of Personality and Social Psychology, 84, 126-147.

Murray, S.L., Derrick, J., Leder, S., \& Holmes, J. G. (2007). Unpublished data, University at Buffalo, State University of New York.

Murray, S.L., Griffin, D. W., Rose, P., \& Bellavia, G. (2003). Calibrating the sociometer: The relational contingencies of self-esteem. Journal of Personality and Social

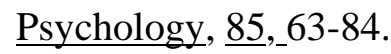

Murray, S. L., Griffin, D. W., Rose, P., \& Bellavia, G. (2006). For better or worse? Self-esteem and the contingencies of acceptance in marriage. Personality and Social Psychology Bulletin, $\underline{\text { 32, 866-882. }}$

Murray, S. L., Holmes, J. G., \& Collins, N. L. (2006). Optimizing assurance: The risk regulation system in relationships. Psychological Bulletin, 132, 641-666.

Murray, S. L., Holmes, J. G., \& Griffin, D. W. (2000). Self-esteem and the quest for felt security: How perceived regard regulates attachment processes. Journal of Personality and Social Psychology, 78, 478-498.

Murray, S. L., Holmes, J. G., MacDonald, G., \& Ellsworth, P. (1998). Through the looking glass darkly? When self-doubts turn into relationship insecurities. Journal of Personality and Social Psychology, 75, 1459-1480.

Murray, S. L., Griffin, D. W., Rose, P., \& Bellavia, G. (2006). For better or worse? Self-esteem and the contingencies of acceptance in marriage. Personality and Social Psychology Bulletin, $\underline{32}$, 866-880. 
Murray, S.L., Rose, P., Bellavia, G., Holmes, J., \& Kusche, A. (2002). When rejection stings: How self-esteem constrains relationship-enhancement processes. Journal of Personality and Social Psychology, 83, 556-573.

Nezlek, J. B., Kowalski, R. M., Leary, M. R., Blevins, T., \& Holgate, S. (1997). Personality moderators of reactions to interpersonal rejection: Depression and trait self-esteem. Personality and Social Psychology Bulletin, 23, 1235-1244.

Pierce, T., Lydon, J. (1998). Priming relational schemas: Effects of contextually activated and chronically accessible interpersonal expectations on responses to a stressful event. Journal of Personality and Social Psychology, 75, 1441-1448.

Reis, H. T., Clark, M. S., \& Holmes, J. G. (2004). Perceived partner responsiveness as an organizing construct in the study of intimacy and closeness. In D. Mashek \& A. P. Aron (Eds.), Handbook of closeness and intimacy (pp. 201-225). Mahweh, NJ: Lawrence Erlbaum.

Rholes, S. W., Simpson, J. A., \& Orina, M. M. (1999). Attachment and anger in an anxiety-provoking situation. Journal of Personality and Social Psychology, 76, 940-957.

Rusbult, C. E., Verette, J., Whitney, G. A., Slovik, L. F., \& Lipkus, I. (1991). Accomdation processes in close relationships: Theory and preliminary research evidence. Journal of Personality and Social Psychology, 60, 53-78.

Simpson, J. A., Rholes, W. S., \& Phillips, D. (1996). Conflict in close relationship: An attachment perspective. Journal of Personality and Social Psychology, 71, 899-914.

Tooby, J., \& Cosmides, L. (1996). Friendship and the banker's paradox: Other pathways to the evolution of adaptations for altruism. Proceedings of the British Academy, $\underline{88}, 119-143$. 